\title{
ESTADOS UNIDOS DE AMÉRICA. UN SIGLO DE CAMBIOS EN LA DISTRIBUCIÓN ESPACIAL DE SU POBLACIÓN. DATOS Y CONSIDERACIONES
}

\author{
José María SERRANO ${ }^{(1)} *$
}

\section{RESUMEN}

Tal vez no es fácil encontrar ningún otro país en el Planeta donde se haya producido semejante movilidad espacial de su población. Su propia génesis histórica ha sido causa fundamental de esta peculiar evolución dinámica del territorio y su poblamiento. De todas maneras el proceso tan acusado de su redistribución poblacional dista de haberse acabado por el momento. En este artículo se analizan y muestran algunas reflexiones sobre ese asunto. Se apuntan cuáles son las principales tendencias seguidas durante los últimos decenios, así como los cambios regionales más notables sucedidos. Además, por supuesto, junto al análisis de los hechos interesa indagar acerca de las causas que los motivan. Tal vez, eso permite, sino avizorar el futuro, al menos intuir cuáles son los presumibles comportamientos inmediatos.

Palabras clave: Densidades de población; movimientos migratorios; diferencias regionales.

\begin{abstract}
The United States of America. A century of changes in the spatial distribution of its population. Data and reflections

Perhaps it is not easy to find another country in the World which has undergone such spatial mobility of population. Its own historic origins might have been the main reason for this peculiar organization and dynamics of territorial evolution. In any case, the process of its huge population redistribution is not complete at the moment. Some reflectins about this process are dealt with in the present article. The main tendencies followed during the last few decades are highlighted, as well as the most noticeable
\end{abstract}

1 Es de justicia señalar mi reconocimiento y gratitud al Department of Geography, University of Southern California, Los Ángeles, California; durante varias semanas recibí en él ayuda y colaboración para la investigación que llevaba a cabo, este artículo abarca una parte de la misma; si bien se desarrolla de forma muy resumida, dadas las limitaciones inherentes, propias de su naturaleza.

* Universidad de Murcia. 
regional changes that have taken place. Besides, together with the analysis of facts, it is an absolute priority to find out the reasons for those changes. May be this allows us to either foresee the future or at least to guess the immediate beaviours.

Key words: Population density; Migratory flow; Regional differences.

\section{Introducción y planteamiento del tema}

La historia de la humanidad está plena de desplazamientos de la población entre unas y otras regiones. De tal suerte que hay quien ha dicho que aquélla no es más que la concatenación sucesiva de movimientos migratorios. De todas formas, por diversas circunstancias, de sobra conocidas, casi todo lo que genéricamente llamamos Viejo Mundo, cuenta, desde hace siglos - a veces incluso tantos que se pierden en los umbrales de la Historia-, con pueblos que están asentados de manera más permanente en un territorio. Y sólo muy ligeramente han modificado y alterado sus límites. Tal vez por ello, aún sin desearlo, nuestra óptica al enfocar y estudiar este asunto, nos induce a hacerlo desde esa perspectiva. Acaso por ello resalta con mayor fuerza el modelo que ofrecen los denominados «países nuevos». Éstos han sido el resultado, en mayor o en menor medida, de procesos de poblamiento en tiempos recientes por colectivos humanos diferentes a quiénes eran sus antiguos moradores. Pues bien, dentro de ese paradigma los Estados Unidos de Norteamérica (en adelante, para abreviar, emplearé las siglas USA, en referencia a la denominación de este país en el idioma mayoritariamente hablado allí), constituyen quizás el exponente más genuino. Por dos razones básicas: Una porque es difícil encontrar otro territorio, de las dimensiones de ese país y de su volumen demográfico, donde la población autóctona actual sea más exigua que la allí contabilizada en el presente. Se ha llegado a ello, por causas históricas de sobra conocidas, aunque muchas veces hábilmente camufladas y disimuladas. Otra, porque el volumen de población que ha ido arribando a las tierras de Estados Unidos es tan numeroso que supera con creces los registrados en otros países cuyo modelo de poblamiento pueda asemejarse al suyo, caso de Argentina, Canadá, Australia, etc.

Por otro lado, aunque los inicios de la corriente inmigratoria en USA sobrepasa ya los tres siglos, sólo en la centuria anterior y en la presente es cuando se contabilizan los mayores volúmenes de inmigrantes. En ese sentido, es un fenómeno más reciente de lo que a simple vista parece. Y, desde luego, a la vista de lo sucedido en los últimos decenios, dista mucho de haber finalizado del todo.

Las enormes riquezas que encierran los Estados Unidos, y el éxito económico que desde hace tiempo viene siendo consustancial con el devenir de esa nación, no ha hecho más que servir de continuo acicate para la llegada progresiva de nuevos contingentes de población que buscaban cobijo dentro de sus fronteras. El denominado «milagro americano», también «sueño americano» (WEISS, R., 1990) se presenta como una meta de la que muchos quieren ser copartícipes.

Al mismo tiempo, la propia tendencia del comportamiento de la sociedad de Estados Unidos, ha ido configurando una serie de «fronteras interiores» que significaban un reto para los continuos desplazamientos de población dentro del país. De ahí la importancia y significación tan notable que los cambios demográficos espaciales señalados suponen dentro del mismo. Si en cualquier estado moderno siempre se advierte una cierta movilidad territorial de sus efectivos demográficos, aquí ese proceso es más vivo y acusado. Al análisis de ello dedicaré las páginas que siguen. 
Paralelamente la evolución interior de la economía y la sociedad americanas vienen mostrando desde hace tiempo una enorme capacidad de cambio y renovación. Se generan nuevas fuentes de riqueza como motores de su desarrollo económico. Y éstas, muchas veces, se sustentan en actividades productivas que precisan de nuevas localizaciones espaciales. Todo ello con independencia de lo que constituye la esencia y la base de la específica capacidad de regeneración y readaptación de sus modelos espaciales de hábitat. El paso de formas rurales a urbanas, y dentro de estas últimas, la complejidad de organización de los espacios urbanizados con tipologías metropolitanas, etc. etc. no hacen más que contribuir a esa movilidad espacial de la población que encuentra en USA su mayor exponente.

Una hipótesis inicial de trabajo indica que, si bien no creo se tienda hacia una homogeneización completa del reparto territorial de los efectivos demográficos, desde luego parece fuera de dudas que se camina hacia un mayor equilibrio. Es una afirmación sobre la que no cabe albergar muchas dudas. Otra cosa bien diferente es el ritmo que sigue y su propio comportamiento espacial. Quiero precisar de antemano que mi atención se centrará en lo sucedido exclusivamente en el Siglo XX, al cual le resta poco por finalizar. Dada la amplitud y complejidad del asunto me limitaré a trabajar con valores globales y escalas de análisis de tal nivel que permitan conseguir una visión de conjunto, siendo imposible descender a estudios de detalle reducidos.

\section{Aumento de la población y llegada de inmigrantes}

Resulta de sobra conocido el espectacular aumento de la población en USA durante el devenir de su corta historia como nación. A título de ejemplo se recogen en el cuadro que sigue los datos referidos sólo a este siglo XX.

Al observar atentamente los datos de este cuadro, y de manera muy sucinta, es posible destacar los siguientes aspectos:

a) Durante los 90 años transcurridos la población no ha cesado de crecer a fuerte ritmo. En datos absolutos eso ha supuesto un aumento nada menos que de 172,5 millones de

Cuadro 1

AUMENTO DE LA POBLACIÓN EN USA. VALORES ABSOLUTOS, (EN MILLONES DE HABITANTES)

\begin{tabular}{|cr|rr|c|}
\hline & & & b & c \\
\hline 1900 & 76,20 & $1900-1910$ & 16,0 & 20 \\
1910 & 92,20 & $1911-1920$ & 13,8 & 19 \\
1920 & 106,00 & $1921-1930$ & 17,2 & 22 \\
1930 & 123,20 & $1931-1940$ & 9,0 & 12 \\
1940 & 132,20 & $1941-1950$ & 19,1 & 25 \\
1950 & 151,32 & $1951-1960$ & 28,0 & 37 \\
1960 & 179,32 & $1961-1970$ & 24,0 & 31 \\
1970 & 203,30 & $1971-1980$ & 23,2 & 31 \\
1980 & 226,54 & $1981-1990$ & 22,2 & 29 \\
1990 & 248,71 & & & \\
\hline
\end{tabular}

a: Evolución de la población total; b: Incremento de la población en los períodos decenales; c: Porcentajes de incremento decenal.

Fuente: Elaboración propia sobre datos de los respectivos Censos. Statistical Abstract. 
personas. En valores porcentuales significa algo más que la multiplicación por tres de los efectivos existentes en 1900.

b) Aunque el ritmo de crecimiento sufre ciertas alteraciones de unos decenios a otros, en todos los intercensales se contabilizan valores muy positivos. El más débil de todos corresponde a la década de los años treinta, donde sólo se consigue un aumento de 9.0 millones de personas. Por contra, es en los años cincuenta cuando se registra el más cuantioso, 28,0 millones de nuevos residentes. Aunque hay otras causas plurales detrás de esas variaciones, sin duda influyó mucho en ese comportamiento, el fuerte cambio que supuso frente a la depresión económica padecida durante buena parte de los años treinta, el auge que se vivió en el decenio siguiente (KNOX, P.I. et al. 1988).

c) De todas formas, y considerando lo que significan estos incrementos de población en su referencia porcentual sobre el total de los efectivos demográficos existentes, se comprueba el ritmo de ascenso de la población se mantiene. Durante las primeras décadas del siglo se movía entre 15 y 20 puntos de incrementos decenales; tras la inflexión, antes referida (años treinta); en el decenio siguiente se produce una clara recuperación, que, con altibajos, se mantiene hasta 1980, descendiendo con posterioridad. Y en los tres últimos períodos censales gana cada uno valores que sobrepasan ligeramente o se acercan a los 30 puntos.

d) Se constata, pues, la idea de que la población de USA sigue creciendo a un ritmo elevado, bastante por encima de lo que suele ser habitual en países de su órbita cercana y con parecido nivel de desarrollo socioeconómico. El gráfico 1 puede ayudarnos a visualizar el comportamiento de tal tendencia.

Desde luego detrás de ese incremento constante de los efectivos demográficos se encuentra no sólo un notable aumento vegetativo, sino, lo que ya se ha referido, la llegada continuada de inmigrantes. Así, en datos globales cabe afirmar que entre 1820 y 1995 USA recibe una cifra cercana a los 60 millones de personas. Sólo en lo que se refiere a este siglo, para ajustarme al período temporal de análisis fijado, el total se aproxima a los cuarenta millones de personas. Los datos se desglosan en el cuadro 2.

Cuadro 2

INMIGRANTES LLEGADOS A USA

\begin{tabular}{|ccr|}
\hline & Número & Tasa \\
\hline $1901-10$ & 8,795 & 10,4 \\
$1911-20$ & 5,736 & 5,7 \\
$1921-30$ & 4,107 & 3,5 \\
$1931-40$ & 0,528 & 0,4 \\
$1941-50$ & 1,035 & 3,5 \\
$1951-60$ & 2,515 & 1,5 \\
$1961-70$ & 3,322 & 1,7 \\
$1971-80$ & 4,493 & 2,1 \\
$1981-90$ & 7,338 & 2,5 \\
\hline
\end{tabular}

Número: millones de inmigrantes llegados; Tasa porcentual media: en relación a la población residente.

Fuente: Elaboración propia sobre datos de Statistical Abstract. 


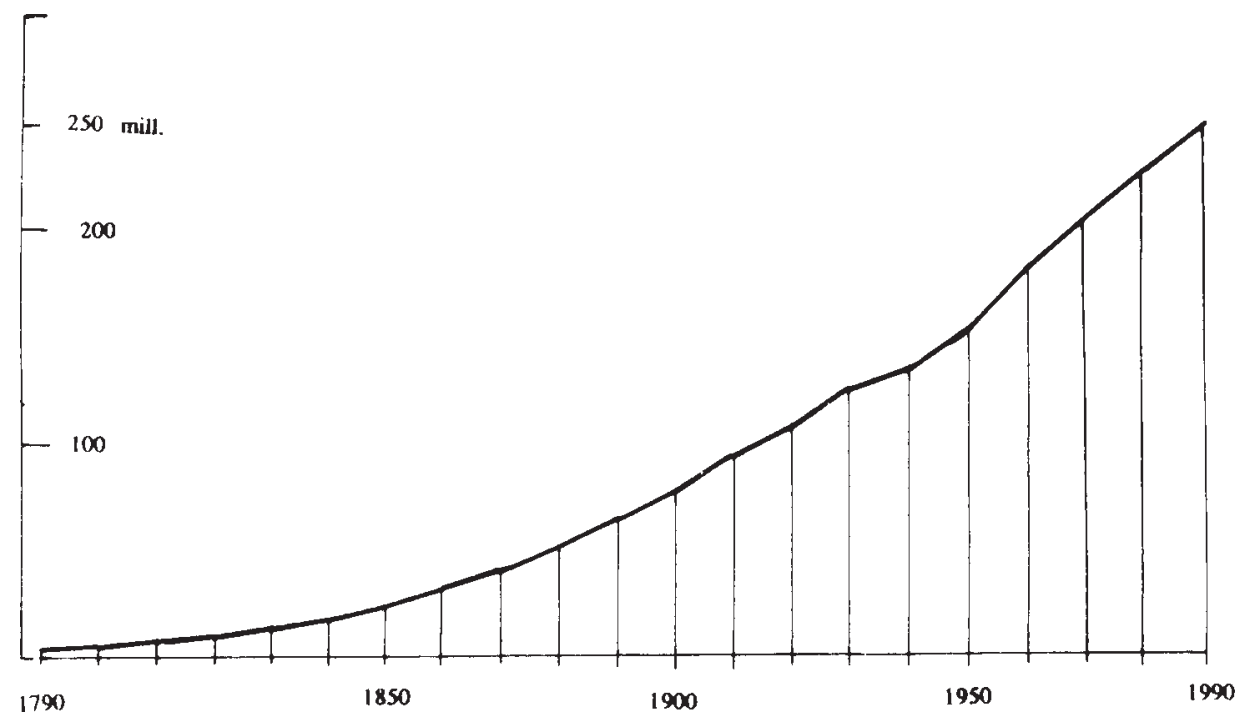

Figura 1. Crecimiento de la población en Estados Unidos. 1790-1990.

No cabe duda que estamos ante un auténtico fenómeno inmigratorio de trascendencia mundial. Dada su especial significación ha sido objeto de numerosos estudios (MITCHELL, R.; GROVES, P. eds., 1987), por lo que, tal vez, no merece la pena insistir más sobre ello; sólo me interesa resaltar, por cuanto eso supone de especial relevancia para nuestro objetivo central, lo siguiente:

$\left.1^{\circ}\right)$ La entrada de inmigrantes no ha cesado en todo ese tiempo. Aunque decenalmente se comprueba la existencia de apreciables oscilaciones. Comienza a principios de siglo con volúmenes bastante elevados que, poco a poco, se amortigua en los años sucesivos. Así se llega a la inflexión más acusada de los años treinta, para, a continuación, irse incrementando poco a poco, hasta el momento actual.

$\left.2^{\circ}\right) \quad$ Se comprueba una cierta coincidencia en la evolución de la llegada de inmigrantes y las variaciones que experimenta el total de sus efectivos demográficos. Lo cual confirma la relación entre ambos fenómenos, a la vez que la superposición de causas estructurales similares entre los dos.

$3^{\circ}$ ) Sin embargo, como muestra la figura 2, el porcentaje de significación de los inmigrantes sobre el conjunto de sus efectivos poblacionales ha ido disminuyendo al paso de los años. Así de representar aquellos cerca del cuarenta por ciento en referencia al total, se ha pasado en estos finales del siglo a poco más del diez por ciento.

$\left.4^{\circ}\right) \quad$ No obstante, no debe olvidarse que las cifras de inmigrantes recogidas en las estadísticas oficiales, también dependen en buen grado, de los vaivenes que sigue la política y la normativa migratoria. Procesos de regulación, normalización, etc., sirven para aumentar sustancialmente los valores globales de inmigrantes. A veces sus efectos son inmediatos; en otros son más lentos.

Todo este plural y complejo colectivo de inmigrantes que sucesivamente arriban a USA, aunque se trata de grupos de personas de muy diferente naturaleza, y que por tanto, 


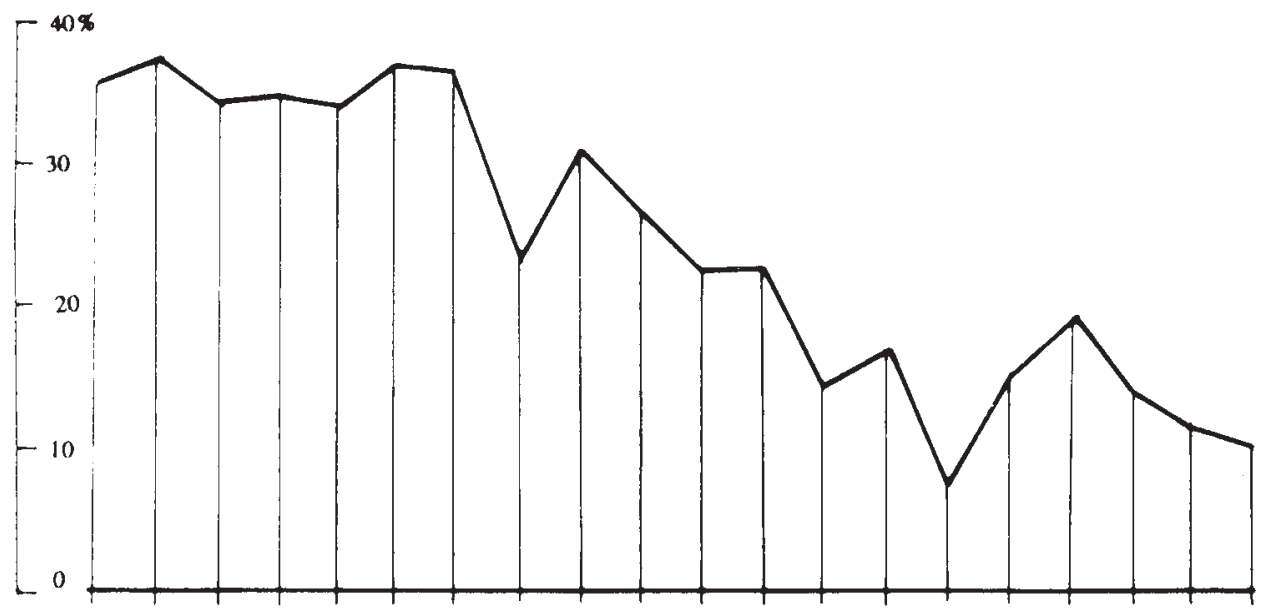

FIGURA 2. Porcentaje de la población inmigrante sobre el censo anterior.

fijan su residencia en lugares muy dispares, que por otro lado, cambian a lo largo de la serie temporal analizada, constituyen un conjunto de personas que influyen bastante en lo que han sido los cambios y las modificaciones experimentadas por la densidad global de la población americana en su conjunto y, de sus unidades estatales y regionales. Hecho que analizaré con más detalle en el epígrafe siguiente.

\section{Variaciones más significativas en las densidades de población en USA}

Según se especifica en el cuadro 3, la densidad general de población en USA ha ascendido a lo largo del siglo XX, desde 8 habitantes por kilómetro cuadrado en 1900 hasta 1990 cuando se alcanza una densidad media de 26. A pesar de que es una subida muy significativa, (algo más de triplicarse), en los finales del Siglo XX, la densidad de población dista de parecerse a los valores medios registrados en la mayor parte de los países europeos. Y, por supuesto, queda muy por detrás de otras cifras contabilizadas en varios países del planeta. Eso, en principio, muestra la posibilidad y el potencial de crecimiento que, por el momento, encierra la población de Estados Unidos.

Si se observan cuáles son las variaciones entre los diferentes Estados que integran la Unión, e incluso lo que sucede en las grandes regiones de USA, se detecta la existencia de acusados contrastes. Estos existían ya en el momento de inicio de este análisis, pero igualmente perduran muchos de ellos en el momento actual. El cuadro 3 especifica con mayor detalle la evolución de estas magnitudes y sus variaciones:

Para conseguir una visión más exacta de lo sucedido, se ha recurrido a la representación cartográfica de todo ello. Al efecto se han confeccionado seis mapas, figuras 3 a 8 . En cada uno se representan las densidades medias de población de los respectivos estados en 1900, 1950, 1960, 1970, 1980 y 1990. Paso a continuación a señalar de forma sucinta algunos de los aspectos más destacados derivados de todo ello:

$1^{\circ}$ ) La densidad media conjunta del país, como se ha apuntado antes, conoce un espectacular cambio a lo largo del siglo. Pasa de 8 habitantes kilómetro cuadrado en 1900 a 26 en 1990. A su vez, durante la primera mitad del siglo la variación es apreciable, 
Cuadro 3

EVOLUCIÓN DE LAS DENSIDADES DE POBLACIÓN

\begin{tabular}{|c|c|c|c|c|c|c|c|}
\hline & Extensión & 1900 & 1950 & 1960 & 1970 & 1980 & 1990 \\
\hline \multicolumn{8}{|l|}{ NORESTE } \\
\hline Nueva Inglaterra & 172.681 & 32 & 53 & 60 & 68 & 71 & 76 \\
\hline Maine & 86.156 & 8 & 10 & 11 & 11 & 13 & 14 \\
\hline New Hampshire & 24.032 & 17 & 22 & 25 & 30 & 36 & 44 \\
\hline Vermont & 24.900 & 13 & 15 & 15 & 17 & 20 & 22 \\
\hline Massachusets & 21.456 & 130 & 218 & 239 & 265 & 267 & 280 \\
\hline Rhode Island & 3.140 & 136 & 252 & 273 & 302 & 301 & 319 \\
\hline Connecticut & 12.997 & 69 & 154 & 195 & 233 & 239 & 252 \\
\hline Atlántico medio & 264.706 & 58 & 113 & 129 & 140 & 138 & 142 \\
\hline Nueva York & 127.189 & 57 & 116 & 131 & 143 & 138 & 141 \\
\hline Nueva Jersey & 20.169 & 93 & 239 & 300 & 355 & 365 & 383 \\
\hline Pensilvania & 117.348 & 53 & 89 & 96 & 100 & 101 & 101 \\
\hline Global & 437.387 & 48 & 90 & 102 & 112 & 112 & 116 \\
\hline \multicolumn{8}{|l|}{ OESTE MEDIO } \\
\hline Centro NO & 647.720 & 24 & 47 & 56 & 62 & 64 & 65 \\
\hline Ohio & 107.044 & 38 & 74 & 90 & 99 & 100 & 101 \\
\hline Indiana & 93.720 & 26 & 41 & 49 & 55 & 58 & 59 \\
\hline Illinois & 145.934 & 33 & 59 & 69 & 76 & 78 & 78 \\
\hline Michigan & 151.586 & 15 & 42 & 51 & 58 & 61 & 61 \\
\hline Wisconsin & 145.436 & 14 & 23 & 27 & 30 & 32 & 33 \\
\hline Centro NW. & 1.341 .167 & 7 & 10 & 11 & 12 & 12 & 13 \\
\hline Minnesota & 218.601 & 8 & 13 & 15 & 17 & 18 & 20 \\
\hline Iowa & 145.753 & 15 & 17 & 18 & 19 & 19 & 19 \\
\hline Missouri & 180.516 & 17 & 21 & 23 & 23 & 27 & 28 \\
\hline Dakota del Norte & 183.119 & 1 & 3 & 3 & 3 & 3 & 3 \\
\hline Dakota del Sur & 199.730 & 2 & 3 & 3 & 3 & 3 & 3 \\
\hline Nebraska & 200.350 & 5 & 6 & 7 & 7 & 7 & 7 \\
\hline Kansas & 213.098 & 6 & 8 & 10 & 10 & 11 & 11 \\
\hline Global & 1.984 .887 & 13 & 22 & 26 & 28 & 29 & 30 \\
\hline \multicolumn{8}{|l|}{ SUR } \\
\hline Atlantico Sur & 722.420 & 14 & 29 & 35 & 42 & 51 & 60 \\
\hline Delaware & 5.295 & 34 & 60 & 84 & 103 & 112 & 125 \\
\hline Maryland & 27.092 & 43 & 86 & 114 & 144 & 115 & 176 \\
\hline Distrito de Columbia & 178 & 1567 & 4505 & 4292 & 4252 & 3584 & 3410 \\
\hline
\end{tabular}


Cuadro 3

(Continuación) EVOLUCIÓN DE LAS DENSIDADES DE POBLACIÓN

\begin{tabular}{|c|c|c|c|c|c|c|c|}
\hline Virginia & 105.586 & 17 & 31 & 37 & 44 & 50 & 58 \\
\hline Virginia del Oeste & 62.759 & 15 & 31 & 29 & 27 & 31 & 28 \\
\hline Carolina del Norte & 136.413 & 13 & 29 & 33 & 37 & 43 & 48 \\
\hline Carolina del Sur & 80.582 & 16 & 26 & 29 & 32 & 38 & 43 \\
\hline Georgia & 152.576 & 14 & 22 & 25 & 30 & 35 & 42 \\
\hline Florida & 151.939 & 3 & 18 & 32 & 44 & 64 & 85 \\
\hline Centro Sureste & 471.242 & 16 & 24 & 25 & 27 & 31 & 32 \\
\hline Kentucky & 104.660 & 20 & 28 & 29 & 30 & 34 & 35 \\
\hline Tennesse & 109.152 & 18 & 30 & 32 & 35 & 42 & 44 \\
\hline Alabama & 133.515 & 13 & 22 & 24 & 25 & 29 & 30 \\
\hline Missisipi & 123.515 & 12 & 17 & 17 & 17 & 20 & 20 \\
\hline Centro Suroeste & 1.133 .647 & 5 & 12 & 14 & 17 & 20 & 23 \\
\hline Arkansas & 137.754 & 9 & 13 & 12 & 13 & 16 & 17 \\
\hline Luisiana & 123.677 & 11 & 21 & 26 & 29 & 34 & 34 \\
\hline Oklahoma & 181.186 & 4 & 12 & 12 & 14 & 16 & 17 \\
\hline Texas & 691.030 & 4 & 11 & 13 & 16 & 20 & 24 \\
\hline Global & 2.327.309 & 10 & 20 & 23 & 26 & 32 & 36 \\
\hline \multicolumn{8}{|l|}{ OESTE } \\
\hline Montañas & 2.336 .627 & 0,7 & 2 & 3 & 3 & 5 & 6 \\
\hline Montana & 380.848 & 0,6 & 1 & 1 & 1 & 2 & 2 \\
\hline Idaho & 216.432 & 0,7 & 2 & 3 & 3 & 4 & 4 \\
\hline Wyoming & 253.326 & 0,3 & 1 & 1 & 1 & 1 & 1 \\
\hline Colorado & 269.595 & 2 & 4 & 6 & 8 & 10 & 12 \\
\hline Nuevo Méjico & 314.925 & 0,6 & 2 & 3 & 3 & 4 & 4 \\
\hline Arizona & 295.260 & 0,4 & 2 & 4 & 4 & 6 & 7 \\
\hline Utah & 219.889 & 1 & 3 & 4 & 4 & 6 & 7 \\
\hline Nevada & 286.352 & 0,1 & 0,5 & 0,9 & 1,7 & 2,7 & 4 \\
\hline Pacífico & 2.386 .406 & 1 & 6 & 8 & 11 & 13 & 16 \\
\hline Washington & 176.479 & 2 & 13 & 16 & 19 & 23 & 27 \\
\hline Oregón & 251.419 & 1 & 6 & 7 & 8 & 10 & 11 \\
\hline California & 411.049 & 3 & 25 & 38 & 48 & 57 & 72 \\
\hline Alaska & 1530.700 & 0,04 & 0,08 & 0,14 & 0,19 & 0,26 & 0,35 \\
\hline Hawai & 16.759 & 9 & 29 & 37 & 49 & 57 & 66 \\
\hline Global & 4.623 .033 & 0,9 & 4 & 6 & 7 & 9 & 11 \\
\hline ESTADOS UNIDOS & 9.372 .033 & 8 & 16 & 19 & 21 & 24 & 26 \\
\hline
\end{tabular}

Fuente: Elaboración propia sobre datos de los Censos Decenales. Statistical Abstract. 
justamente se duplica, sube a 16. Después, en los últimos cuatro decenios va ascendiendo progresivamente, 19, 21, 24, hasta el valor final antes referido.

$2^{\circ}$ ) En el momento de partida, 1900, ya se comprueba la existencia de importantes diferencias en todo el territorio de la Unión. Se trata de unos contrastes que, aunque se mitigan poco a poco al paso del tiempo, en el momento presente siguen siendo espectaculares. Así, a título de ejemplo, y tomando como unidad de análisis el marco de los Estados de la Unión, basta contrastar los 383 habitantes de Nueva Jersey, con los 0,35 de Alaska. Sin recurrir esos valores tan extremos, son abultadas las diferencias existentes entre el conjunto del Noreste, con cifras medias de 116 h. $/ \mathrm{km}^{2}$, frente a los 11 del Oeste.

Tal vez por ello puede resultar de interés indicar algunas matizaciones relativas a la evolución seguida por las distintas unidades territoriales de USA a través de los últimos decenios. En ese sentido, al comprobar las variaciones especificadas en la tabla de datos y representadas en las figuras correspondientes, ( 3 a 8 , ambas inclusive) se comprueba como hechos más significativos, entre otros, los que, de forma resumida, añado a renglón seguido.

\subsection{Mantenimiento de las tendencias espaciales tradicionales hasta 1950}

En 1950 sobresale con especial relevancia la concentración de la población en varios de los Estados del Noreste, como la región con mayores densidades, superiores a los 90 h. $/ \mathrm{km}^{2}$. Incluso en algunos Estados de Nueva Inglaterra se supera esa cifra; Massachusets, Connecticut, Rhode Island; también en otros del Atlántico Medio, Nueva York, Nueva Jersey y Pensilvania. Hacia el Sur, sólo el Distrito de Columbia supera ese umbral. En las proximidades de los Grandes Lagos, si bien el incremento poblacional conseguido durante la primera mitad de este siglo es notable, ni siquiera Ohio, el de mayor densidad de población, sobrepasa ese límite. Otros como Illinois, Michigan e Indiana quedan todavía bastante por detrás del mismo.

También en esa misma fecha la mayoría de los Estados que se extienden desde Virginia a Florida, sus densidades de población casi se duplican. Es el caso de las dos Virginias y en ambas Carolinas. Más hacia el Sur, mientras Georgia incrementa sus niveles de densidad en 8 puntos, Florida lo hace en 15 puntos. Esta última cifra significa, en referencia a la realidad existente cincuenta años antes, una multiplicación por seis de sus efectivos poblacionales, al pasar de una densidad de 3 a $18 \mathrm{~h} . / \mathrm{km}^{2}$. Eso confirma ya el inicio de lo que después sera un tendencia prolongada bastante tiempo.

Los Estados del Centro, Sureste y Suroeste, aunque con menor intensidad, durante este período de tiempo conocen subidas demográficas apreciables; eso ocurre de Kentucky a Texas. Por contra toda la gran región de Centro Noroeste y Oeste, desde Minnesota y Montana hasta Nuevo Méjico y Arizona, aunque con apreciables disimilitudes entre sí, su ritmo del incremento poblacional es mucho más reducido, con frecuencia casi inexistente. Sólo en el Extrema Oeste, Junto a la Costa del Pacífico, registran una evolución más favorable y positiva, con incrementos proporcionales significativos. Sus subidas alcanzan hasta cinco y ocho veces, siempre en referencia a sus efectivos demográficos precedentes.

En definitiva, durante esas cinco décadas, cabe señalar que, a grandes rasgos, continúa la tendencia anterior de modelo de asentamiento y ascenso de la población en USA (JEANNINE, B., 1980). Véanse las figuras 3 y 4 donde se representan tales aspectos. El gran «corazón» inicial del Noreste, donde se acumulan los mayores efectivos de población sigue consolidándose como espacio vital; ahora se adquiere y consolida la morfología propia de las denominadas «megalópolis», según indicó con tino J. GOTTMANN (1961). 


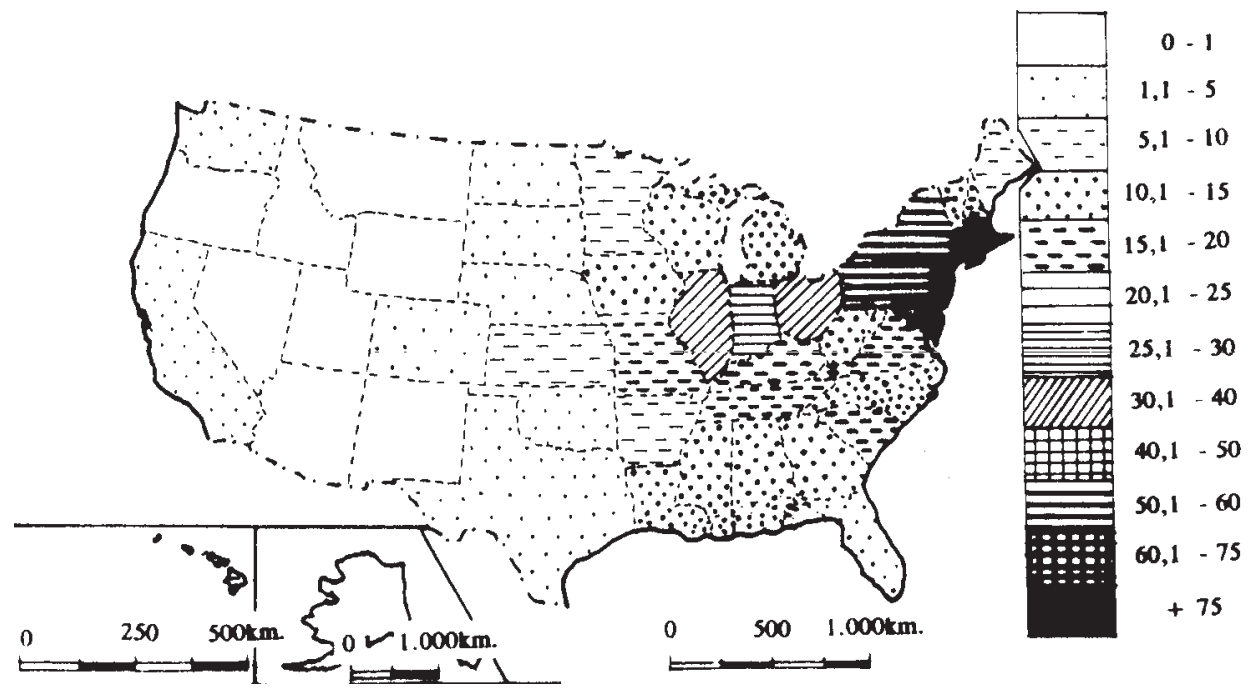

Figura 3. Densidades de población en 1900.

Pero los años de la depresión económica, y la política iniciada por Roosevelt, permitieron dar un cierto empuje favorable a las tierras del Sur, revitalizando sus economías; y, por ende, incrementando sus efectivos demográficos (SCHLESINGER, A.M.J., 1971). También las mejoras en los transportes, entre otras causas, facilitó la marcha hacia el Oeste de mayores efectivos poblacionales (MULLER, P.O., 1986), potenciando lo que había sido toda una tradición iniciada en decenios precedentes (HANSEN, M.L. 1948-51). La irrupción con fuerza, ahora, de los territorios del Pacífico dentro del aumento poblacional, viene a consagrar este territorio como futura área que sirve de balance a la situación disímil, inclinada hacia el Este. En esas tierras se van configurando una serie de centros urbanos de gran dinamismo y significación, que continuará durante las décadas siguientes (ADAMS, J.S., 1976).

\subsection{El período «dorado» de la hegemonía americana}

En sólo diez años, el período situado entre 1950 y 1960, la población del conjunto del país aumenta en 28 millones de personas; pasa de 151,3 a 179,3. Ello significa en la densidad de población global del país, un ascenso de casi tres puntos. Los cambios más significativos para ver como afecta todo ello al conjunto territorial confirman que, persiste, en gran medida, el modelo tradicional de evolución que venía heredado del pasado. Deben contejarse la evolución de estos datos, con lo que recogen las figuras 4 y 5.

Así los estados del Noreste son quienes ven subir su densidad media desde los $90 \mathrm{~h} . / \mathrm{km}^{2}$ a 102. Pero, sin embargo, cabe resaltar un matiz interesante. Mientras Nueva Inglaterra asciende de 53 a 60 en su densidad; los Estados incluidos en la denominada región del Atlántico Medio experimentan mayores alzas, al pasar de 90 a 102 habitantes. Son los años cuando se perfila ya con gran fuerza lo que será, en la década siguiente el auge de la gran megalópolis del Atlántico. El mito que se había ido forjando sobre estas regiones dinámicas de los Estados Unidos continúa en plena vigencia (GHORRA-GOBIN, C., 1987). 


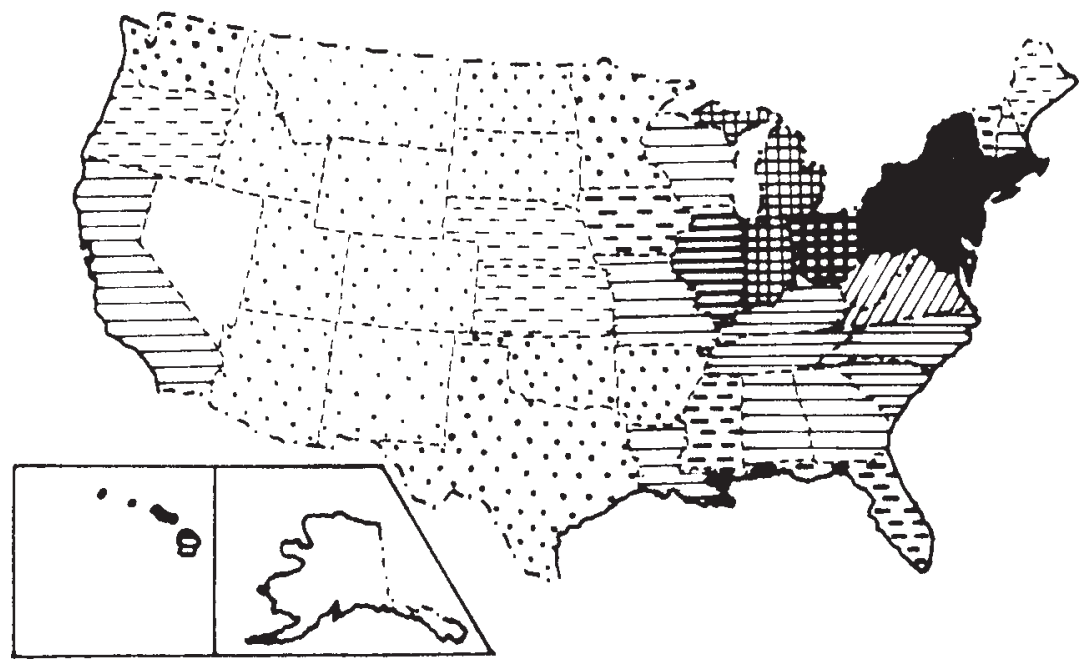

Figura 4. Densidades de población en 1950.

De todas maneras, prosigue el aumento poblacional de las otras grandes regiones de USA. Así, todo el denominado Oeste Medio asciende su densidad de 22 a 26 habitantes. Aunque, dentro de ella, es muy distinto el comportamiento de las dos grandes subregiones que lo integran. Mientras que el Centro Noreste incrementa sus efectivos demográficos en

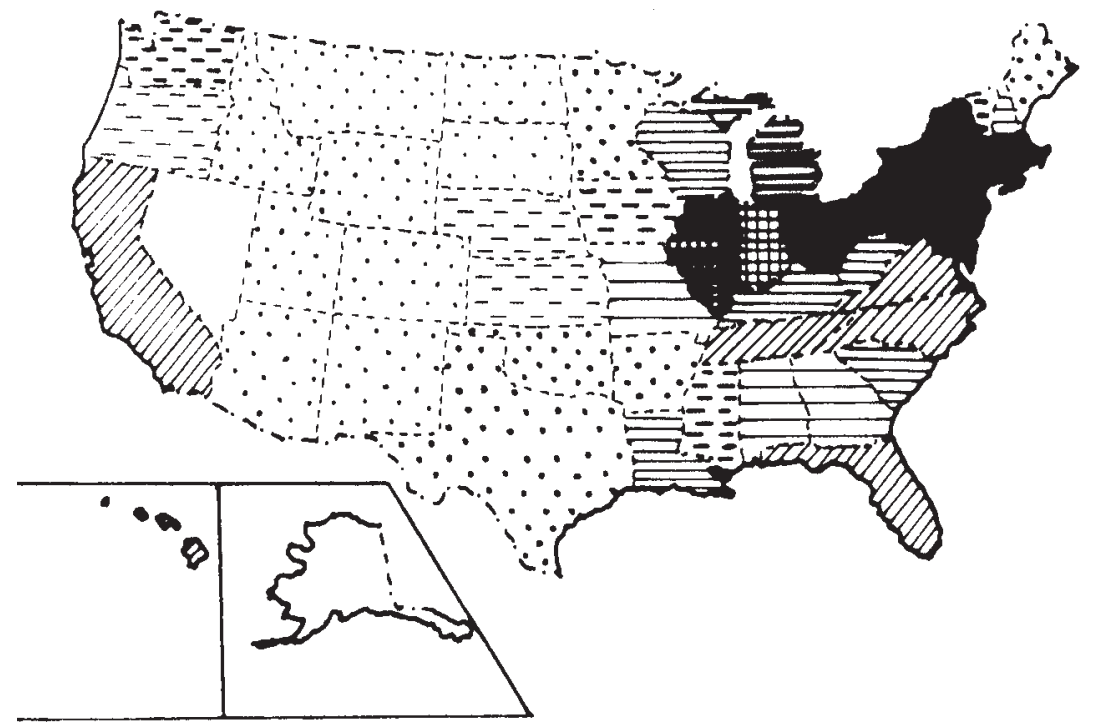

Figura 5. Densidades de población en 1960. 
9 puntos; el centro Noroeste sólo gana 1 punto. Lo cual significa casi una situación de estancamiento. Sin duda las notables diferencias en el equipamiento industrial, durante lo que fue un período de clara expansión y crecimiento urbano subsiguiente, adquiere matices diferenciados de unas a otras regiones. Igualmente los apreciables colectivos inmigratorios (algo más de dos millones y medio) contabilizados esos años, parecen comportarse de forma selectiva a la hora de seleccionar sus lugares de asentamiento (BODNAR, J., 1985).

El conjunto de los estados del Sur suben su densidad demográfica en 3 puntos, pasan de 20 a 23. Una proporción muy similar a la ocurrida al llamado Oeste Medio. Pero se advierten notables diferencias entre sus correspondientes subregiones. Los Estados localizados en el área del Atlántico Sur, de Delaware a Florida, consiguen incrementos mucho más elevados, (en torno a los seis puntos de media); frente a los del Centro-Sureste, con un sólo punto; y los del Centro Suroeste con dos. Territorialmente, cabe, pues, señalar que la dinámica de expansión de la población americana, seguida tradicionalmente, de «mancha de aceite», elige dirigirse primero hacia el Sur, directamente, antes que hacia el Sureste. Los Estados de Florida, Delaware y Maryland se sitúan en cabeza del crecimiento dentro de esa Región. Ahora bien, junto a la dinámica del crecimiento industrial, es preciso añadir otras causas colaterales, caso del ascenso del terciario selectivo, bastante importante en Florida, que ayudan a conseguir ese mayor dinamismo demográfico (BIRDSALL, S.; FLORIN, 1992). En estos años se sitúan los inicios del denominado «sunbelt».

En la extenso Oeste, globalmente, la densidad se incrementa únicamente en dos puntos. No obstante se aprecia dentro de ella un comportamiento distinto en lo que son los Estados ubicados en las «Montañas» donde las densidades de población ascienden de forma muy ligera, frente a lo que sucede en los del Pacífico, con aumentos más significativos. A su vez, dentro de estos últimos, el saldo es realmente muy favorable en California, pues ya por esos años inicia su notable despegue como área de mayor densidad demográfica. La conjunción en ella de una serie de rasgos favorables, de naturaleza económica, justifican este incremento poblacional. En especial ello origina la llegada de notables contingentes de inmigrantes, procedentes tanto desde dentro de la Unión, como desde fuera del país. La red urbana de California que se configura y crece espectacularmente en estos años es buena prueba de ello (JOHNSTON, R.J., 1982). A mayor distancia de la anterior se sitúa Washington o incluso Hawai en el Pacífico.

\subsection{Los cambios producidos durante los años sesenta}

En esos diez años, la población en Estados Unidos crece hasta superar ligeramente los 203 millones de personas. En referencia a 1960, cuando se contabilizaban 179,3, su ascenso es de 24 millones de nuevos ciudadanos. Por su parte, el saldo migratorio significa 3,3 millones de personas. Por supuesto, estas variaciones globales conllevan una subida de la densidad media de población de algo más de dos puntos en el conjunto de USA.

Por encima del comportamiento medio del país, dentro de lo que se consideran las grandes regiones, sobresale el ascenso del Noreste, aquí se pasa en ese decenio de 102 a $112 \mathrm{~h} . / \mathrm{km}^{2}$.; seguido muy de lejos por el Sur, donde se incrementan las medias en más de 3 puntos. El resto de USA anota aumentos modestos; aunque de forma puntual, en unos pocos Estados, se contabilicen variaciones de diferente volumen. Pero, veamos con mayor detenimiento algunos de estos aspectos:

Dentro del Noreste mientras que los Estados de Nueva Inglaterra elevan sus medias en 8 puntos; los del Atlántico Medio lo hacen en 11. Sin duda todavía el impulso dinámico que ha caracterizado a toda esta parte de Estados Unidos durante mucho tiempo continúa en el decenio. Junto al aporte inmigratorio procedente del exterior, que sigue llegando a 


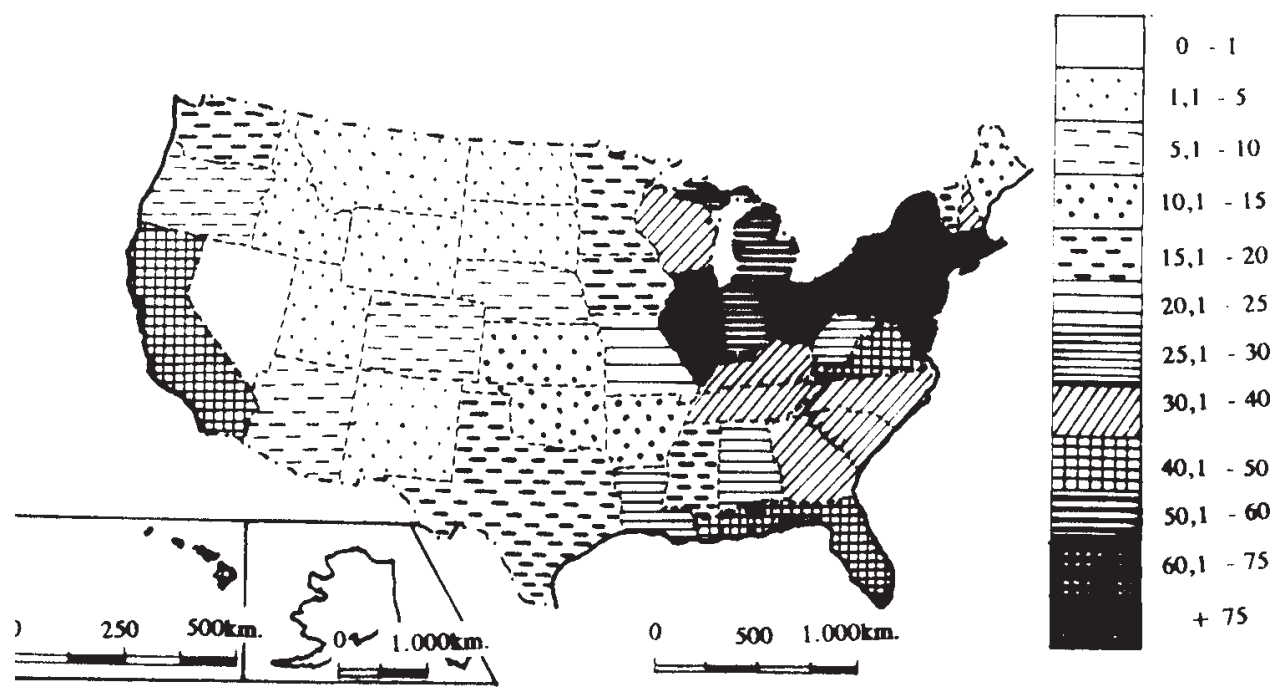

Figura 6. Densidades de población en 1970.

ella, esa área de USA continúa siendo uno de los principales objetivos de los desplazamientos poblacionales interiores (PATERSON, J.H., 1989). Buena parte de lo que es el denso y significativo sistema urbano, y demás áreas metropolitanas del Este, mantienen su proceso de acumulación demográfica, aunque ya no sea tan fuerte como para alcanzar la significación que tuvo en épocas anteriores (BETHEMONT, J.; BREUIL, J.M., 1989).

Por lo que se refiere al Sur, la otra gran área que conoce un balance bastante positivo, registra el mayor dinamismo poblacional de los Estados litorales del Atlántico Sur (ascenso en siete puntos de sus medias); frente a los del Centro Sureste, que sólo crecen dos puntos. Una posición intermedia registran los del Centro Suroeste con ganancias intermedias de tres puntos. Todo ello supone la definitiva confirmación, apuntada ya, de la polarización demográfica desempeñada por el «sunbelt».

Dentro del gran marco territorial del Oeste, la población residente en los Estados de «las montañas» apenas consiguen aumentos apreciables en su densidad demográfica; la excepción que aporta Colorado (ascenso de más de dos puntos), es la única significativa. Todo eso parece confirmarnos que esta gran región comienza a instalarse en una situación de cierta atonía demográfica, lo cual se contrapone a lo que ha venido sucediendo en el resto de la Unión. El contrapunto a este panorama general del Oeste lo aportan los Estados del Pacífico, donde California asciende diez puntos en su densidad poblacional, seguida de lejos por Washington, con 3 puntos. Sin duda la inmigración que viene del Sur, con fuerza, (MCHUGH, K., 1989) ayuda en esta década a lograr buena parte de sus ganancias demográficas, junto con el resto de otras corrientes inmigratorias interiores procedentes del conjunto de la Unión (ARMAND, L.; MARTIN, D.; TOINET, M.F., 1980).

En definitiva pues, en el decenio de los sesenta, prosigue, salvo ciertas excepciones, la tónica dominante de variación espacial de los efectivos humanos en el conjunto de USA; con algunos matices que, someramente, he apuntado. En las figuras 5 y 6 pueden comprobarse tales aspectos. 
3.4. Años setenta: inicio de mayores modificaciones territoriales en la distribución espacial de la población

Se mantiene durante la década la tendencia del crecimiento poblacional. La cifra contabilizada a comienzos de 1970, 203,3 millones de habitantes, sube en 1980 a 226,5 millones. Tal incremento significa una cantidad de 23,2 mill. de nuevos ciudadanos. Al mismo tiempo, la suma de los inmigrantes incorporados a la población de Estados Unidos totalizan 4,4 mill. Eso representa una proporción cercana al 20\%, a pesar de la dimensión que la población de USA alcanza ya en esos años. Tal incorporación de nuevos habitantes, unida a notables variaciones socioeconómicas experimentas por Estados Unidos de manera continua en ese tiempo, se traduce, desde una perspectiva espacial, en significativas modificaciones en sus densidades de población, tal circunstancia puede comprobarse al cotejar los mapas de las figuras 7 y 8.

Mientras que la densidad de población del global de USA se incrementa en tres puntos, al pasar de 21 a 24 hab. $/ \mathrm{km}^{2}$, el comportamiento de sus diferentes Estados y grandes regiones no es homogéneo, como ya viene siendo habitual. De forma muy resumida los principales aspectos más llamativos son:

a) Por primera vez el Noreste deja de aumentar sus densidad (112 hab./ $/ \mathrm{km}^{2}$, la más alta del país), se estancan. Tal comportamiento, a su vez, encierra un pequeño ascenso en los Estados que integran Nueva Inglaterra (incremento de 3), junto a un descenso en los englobados en el Atlántico Medio, (menos dos). De todas maneras resulta llamativo que el Estado de Nueva York, por primera vez en toda su historia, experimenta una disminución de 5 puntos en la densidad de su población; sin duda el paso de un modelo económico basado en la industrialización a otro postindustrial, es un aspecto significativo a resaltar (CLARK, D., 1985); junto, por supuesto, con añadidas causas complejas y plurales, específicas de esta macrorregión que sufre ciertas deseconomías (FREY, W.; SPEARE, A., 1988).

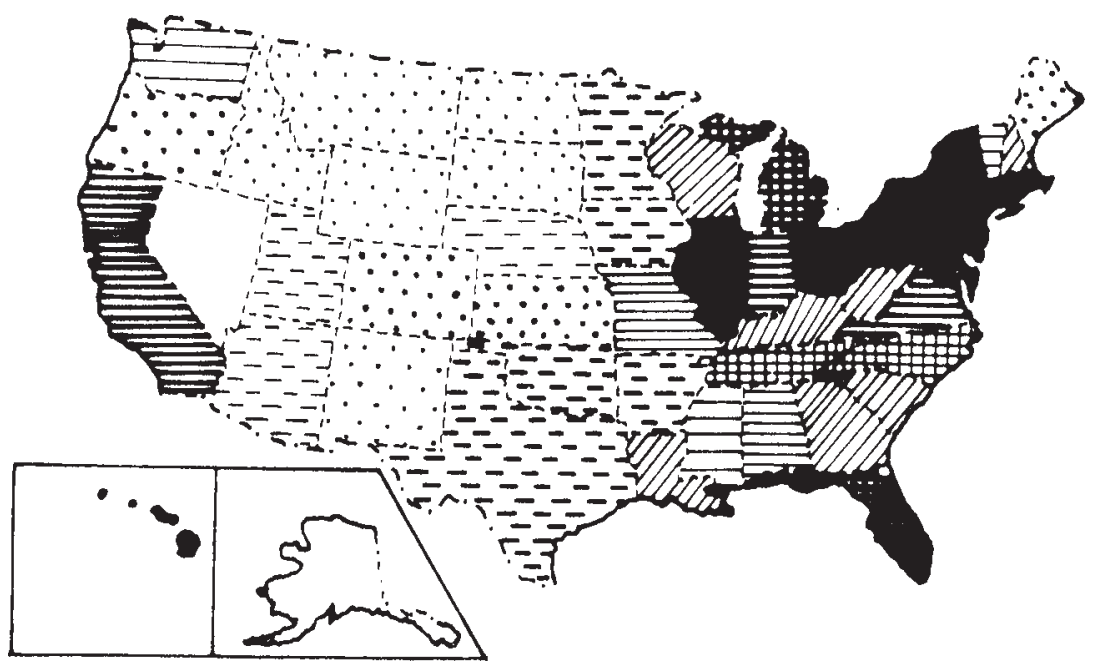

Figura 7. Densidades de población en 1980. 


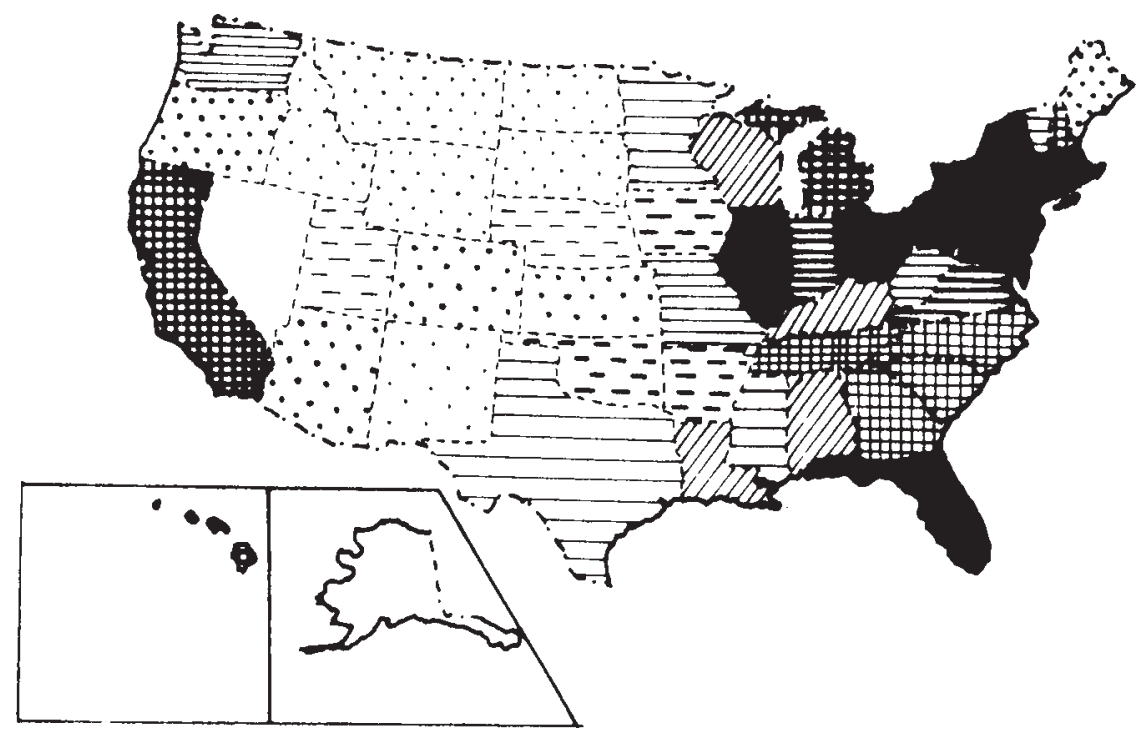

Figura 8. Densidades de población en 1990.

b) De manera contrapuesta el Sur conoce durante la década un balance favorable, aumento de 6 puntos en sus densidades medias (al pasar de 26 a 32). Se trata de un comportamiento más vigoroso al de decenios precedentes. Debe añadirse que junto al efecto ya referido de «sumbelt» se añade ahora el de «manufacturing belt»; con todos las circunstancias que ello supone. A su vez, dentro de esta parte de USA, la región del Atlántico Sur es la que conoce una evolución más vigorosa, con un ascenso de 9 puntos (asciende de 42 a 51 hab. $/ \mathrm{km}^{2}$ ), frente a ganancias más modestas en los Estados del Centro Sureste (4 puntos) y Centro Suroeste (3 puntos). En la primera de ellas, se comprueba que desde Delaware y Maryland hasta Florida se registran constantemente ganancias notables. Cabe entender esa evolución pensando que el dinamismo económico tradicional del Noreste se ha desplazado definitivamente hacia el Sur. Muchas de las viejas estructuras productivas del Noreste no pueden competir frente a los nuevos alicientes que presentan las redes urbanas de los Estados del Sur, mucho más dinámicas en su crecimiento y evolución (BRUNN, S.; WHEELER, J.D., 1980).

c) En menor grado el Oeste, también experimenta una evolución favorable, ascenso de 2 puntos en sus densidades medias de población, pasando de 7 a 9 hab. $/ \mathrm{km}^{2}$. A su vez, dentro de este extenso territorio, es equilibrada la evolución de sus dos grandes subregiones, la de las montañas y la de la Costa del Pacífico. Aunque si nos fijamos en una escala más detallada, el Estado de California, con una ganancia neta de 9 puntos, es quien alcanza en lugar privilegiado en esa evolución. Todo ello hace que se confirme como foco de crecimiento demográfico del Oeste; aunque tímidamente, comienza a servir de contrapeso al desequilibrio tan patente típico de la distribución espacial de la población en Estados Unidos. La evolución positiva del área del Pacífico experimenta en esos años un cierto empuje con un 
desarrollo demográfico, consecuencia de su mayor dinamicidad industrial, y en especial de los servicios; todo lo que propicia el referido cambio poblacional.

d) Una situación de crecimiento moderado, modesto, ocurre en el Oeste Medio (ganancia de un punto). De todas formas, dentro de él, existen ciertas diferencias. Así, mientras que los Estados de la parte oriental consiguen ligeras ganancias (aumento de 2 puntos); los del Oeste sufren un claro estancamiento. Entre los primeros cabe referir balances ligeramente favorables en Indiana, Illinois, Michigan y Wisconsin. Tal vez en estos últimos casos la inercia de la evolución de años anteriores continúa.

En resumen, pues, durante los años setenta a la vez que quiebra, en cierta modo, la tendencia tradicional seguida por el proceso de crecimiento y distribución espacial de la población en USA, las modificaciones poblacionales registradas indican una tendencia hacia un mayor equilibrio territorial en el reparto de los efectivos demográficos. Pero, desde luego, nos encontramos muy lejos de una situación de homogeneidad. Así sobre ese balance se inicia la última década transcurrida.

\subsection{Cambios registrados durante los años ochenta}

Los datos globales, referidos a todo el país confirman que durante el último decenio la población no ha dejado de aumentar; ahora son 22,2 millones los nuevos habitantes contabilizados, alcanzando la cifra conjunta de 248,7. De ahí que la densidad media ascienda de 24 a $26 \mathrm{~h}$ hab. $/ \mathrm{km}^{2}$. En valores absolutos siguen incrementándose las cifras, a un ritmo parecido, al ya referido de los últimos decenios. Ahora bien, en valores relativos ello supone una desaceleración de lo sucedido hasta ahora. Algo parecido ocurre con la aportación de nuevos inmigrantes desde el exterior; su total se eleva hasta 5,3 millones de inmigrantes. Es una cifra algo superior a la de décadas precedentes, pero que sin embargo supone una tasa poblacional similar $(2,5 \%)$; se trata de una proporción algo más elevada que la de decenios inmediatos; pero inferior a la que se venía registrando hasta 1930.

De todas maneras, esta aportación de nuevos inmigrantes, unida a la dinámica migratoria interior, originada por motivaciones socioeconómicas territoriales de diferente signo, propicia apreciables modificaciones en los balances que sufren las diferentes regiones de la Unión, en sus densidades medias de población. Las figuras 7 y 8, junto a los datos del cuadro 3, permiten comprobar cuanto indico. De manera resumida, expongo a continuación, algunos aspectos más significativos referentes a este decenio final estudiado.

Tomando como marco espacial de análisis las cuatro grandes regiones de USA hay dos que obtienen balances más favorables que la media nacional (Noreste y Sur, ambas con ascensos medios de 4 unidades); frente a las otras dos Oeste Medio y Oeste cuyas ganancias respectivas de 1 y 2 puntos, son inferiores o similares al comportamiento medio de todo el país. Da la sensación que cada vez existe un número de matices más elevado, consecuencia de la mayor complejidad que encierra el territorio.

a) El Noreste, área más poblada del conjunto de la Unión, parece que de nuevo ha recuperado su protagonismo económico y demográfico. Así se comprueba que tanto los Estados de Nueva Inglaterra, que aumentan su densidad en 5 puntos, como los de Atlántico Medio, ascenso en sus valores de 4 puntos, se encuentran inmersos en la misma dinámica. Aunque dentro de esta región, todavía quedan unos pocos estados, los más septentrionales, con densidades medias modestas (caso de Maine, New Hampshire y Vermont). Todos los restantes ya superan en 1990 el umbral de los 100 hab./km²; incluso en varios de ellos esa media se ve sobrepasada ampliamente. Tal vez después de 
lo que fue una coyuntura pasajera, la desindustrialización que aquejó sobre todo a un «modelo determinado de actividades y formas de vida, durante los años setenta, esta región de USA ha sabido reaccionar a tiempo con una dinamicidad económica que lleva aparejada su incremento demográfico» (GHORRA-GOBIN, C., 1993).

b) En datos relativos, los Estados del Sur, también registran durante el último decenio un balance positivo en sus densidades demográficas, alza de 4 puntos. Pero dentro de esta área el comportamiento de los diferentes Estados que la integran es disímil. Mientras que los Estados del Atlántico Sur, incrementan su densidad en 9 puntos, hasta alcanzar valores medios de $60 \mathrm{hab} . / \mathrm{km}^{2}$., los del Centro Sureste sólo ganan un punto. Una posición intermedia, si bien más cerca de la primera, consiguen los Estados del centro Suroeste, con ascensos de 4 puntos. Tal tendencia, que engloba comportamientos plurales dentro de una gran área geográfica, ya apuntada con anterioridad, ha sucedido también en decenios anteriores. Ello ha originado una situación dispar en el momento presente, al comprobar que la densidad demográfica de los Estados del Atlántico Sur alcanzan una densidad en torno a los 60 hab. de promedio; frente a los del Centro Sureste con sólo 32, y Centro Suroeste con 23. Da la sensación que la polarización demográfica ejercida por el Noreste continúa extendiéndose, lenta y suavemente hacia el Sur, dejando una cierta bolsa más vacía en el centro (Arkansas, Oklahoma). A ellos ha llegado con mayor debilidad el desarrollo económico industrial y terciario que propicia el crecimiento demográfico. En sentido opuesto, a toda esta área, es Florida, en el extremo Sur; además de Maryland y Delaware, próxima a los Estados del Atlántico Medio, los cuáles caminan en cabeza, con las mayores densidades demográficas.

c) El área del Oeste Medio apenas consigue incrementar sus densidades medias de población. Eso sucede tanto en su parte Oriental como en la Occidental. En ambas sólo se registran incrementos en torno a un habitante por kilómetro cuadrado. De todas maneras son abultadas las diferencias existentes entre los estados comprendidos en su parte Noreste, donde se consiguen valores medios en torno a los 65 hab. $/ \mathrm{km}^{2}$, frente a los del Noroeste que sólo se logran 13. Cabe decir que algunos de los Estados de la primera subárea, en torno a los Grandes Lagos, como Ohio, Illinois, Michigan e Indiana aproximan sus niveles medios de densidades poblacionales a los de la costa del Atlántico Medio. Mientras que en otros del Centro Noroeste, como las dos Dakota o Nebraska encuentran mayores similitudes al compararlas con el área del Oeste; en concreto, con los estados que comprenden las Rocosas, desde el Norte, frontera con Canadá, hasta el Sur, en el límite con Méjico. Se trata por tanto de un espacio de transición entre ambas.

d) Por último en el Oeste, de nuevo resalta la existencia de una clara diferenciación entre lo sucedido en las montañas donde por término medio las densidades poblacionales sólo suben un punto, frente a los Estados del Pacífico que aumentan en 3. Eso origina que, en su globalidad, se registre un ascenso medio de 2 puntos. A su vez, dentro de este último grupo de territorios litorales, resalta el significativo crecimiento demográfico experimentado por California, que en 1990 alcanza ya valores medios superiores a los 72 hab. $/ \mathrm{km}^{2}$; seguido muy de lejos por Washington con 27. California, con su considerable extensión y su volumen demográfico, ha alcanzado con claridad en los finales del Siglo XX un protagonismo indiscutible, al convertirse en centro de un área demográfica y económicamente importante, que abre las puertas hacia un mayor equilibrio territorial conjunto. Aunque, por el momento se está muy lejos de que tal realidad haya alcanzado plena madurez (DEBLIT, H.J.; MULLER, P.O., 1992). Punto y aparte representan Alaska, donde por sus fuertes condicionantes naturales, junto a 
otros circunstancias añadidas va a terminar el Siglo XX con densidades que ni siquie-

ra alcanzan 0,5 habitantes por $\mathrm{km}^{2}$.

Los años ochenta, pues, con ligeras variaciones, mantienen las tendencias señaladas en decenios precedentes. De todas formas, si se coteja la realidad existente a finales del Siglo XX con la de sus inicios, son varios los aspectos que han cambiado; muchas las modificaciones producidas (figura 9). Un balance acompañado de ciertas reflexiones finales se incluyen en el apartado que sigue.

\section{Balance y reflexiones finales}

En definitiva, pues, los grandes cambios en la distribución espacial de la población registrados en USA durante el Siglo XX se deben, en esencia, a tratarse de un país en fase de configuración. Durante este siglo se ha contabilizado un fuerte incremento en sus efectivos demográficos, tanto por su propio crecimiento vegetativo como también por la llegada de importantes corrientes inmigratorias. Al mismo tiempo se ha producido una intensa industrialización que, con posterioridad, ha dado paso a plurales sucesiones de

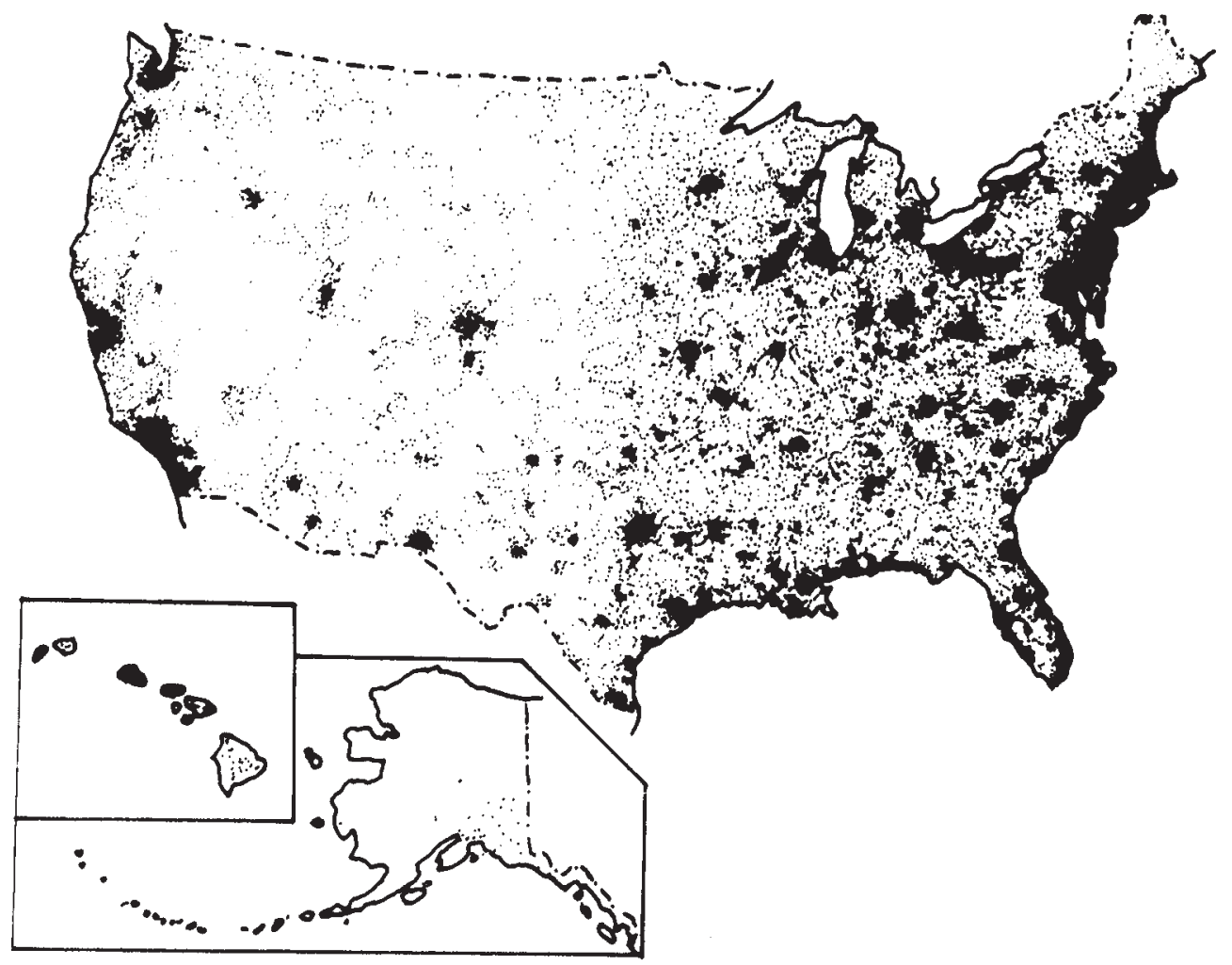

Figura 9. Distribución espacial de la población en Estados Unidos, 1990 (cada punto 10.000 habitantes). 
cambios y reajustes con apreciables casos regionales de postindustrialización, consecuencia de su camino de maduración. La creación de nuevos focos industriales ha supuesto, en muchos casos, alteraciones en la tendencia poblacional. A la vez los sectores económicos primarios han sufrido intensas remodelaciones y modificaciones, disminuyendo sustancialmente sus efectivos ocupacionales. A ello se añaden apreciables períodos de crecimiento del sector servicios, tanto las típicas actividades terciarias, como otras de naturaleza avanzada. La localización de muchas de éstas han seguido pautas locacionales que preferían su instalación en nuevas áreas. Al mismo tiempo debe tenerse presente la intensa urbanización que ha afectado a todo el territorio nacional, si bien con variada y disímil incidencia.

Sobre esas pautas estructurales, que sirven de base, deben resaltarse determinados aspectos concretos de gran significación.

$\left.1^{a}\right)$ La continua llegada de inmigrantes desde el exterior son un aporte fundamental que, dada la elección selectiva de sus lugares de domicilio, han producido de forma diferenciada el incremento de las densidades de población. Así mismo, cabe añadir que al originarse cambios sustanciales en la procedencia de estos inmigrantes, -importancia creciente de «Hispanos»-, desde toda Iberoamérica, y de «asiáticos», igualmente se han modificado sus preferencias en los lugares de asentamiento, lejos ya de la tradicional entrada y destino inicial precedente que fue el Noreste (THOMSON, R., 1969).

$2^{a}$ ) Los movimientos migratorios interiores alcanzan en el conjunto de los Estados Unidos dimensiones mayores que en otras partes del mundo desarrollado, o con entorno socioeconómico similar. Realizar varios traslados de domicilio a lo largo de la vida, tanto laboral, como posterior, parece ser frecuentemente en gran número de familias americanas (HOLLANDER, A.N.J den; SKARD, S., 1968); menos arraigadas, quizás, a sus lugares de origen. La dinámica corriente de la vida americana implica frecuentes cambios de empleo, o simplemente de domicilio. Tal vez, un país de sus dimensiones espaciales y con sus características socieconómicas favorece tal movilidad espacial.

$3^{a}$ ) Las notables modificaciones socioeconómicas, de muy diferente naturaleza, sufridas por Estados Unidos a lo largo de los últimos decenios, han influido enormemente en las consiguientes alteraciones espaciales de reparto de su población. En tal sentido debe abundarse sobre la idea de que ese país durante el siglo XX está inmerso en la empresa de su propia configuración, lo cual encierra la existencia de varios frentes de avance, (caso del sumbelt) en compensación con otras áreas que van quedándose rezagadas (OXFORD REGIONAL ECONOMIC ATLAS, 1994).

A la vez, y sobre esa realidad básica, plural y compleja que impregna y dirige todo, es posible señalar algunos aspectos concretos, ya apuntados, que tienen especial relevancia para el asunto central que nos ocupa. Así, entre los más significativos, me permito indicar algunos a continuación:

a) La dinámica de urbanización ha sido intensa y generalizada, alcanzando a todo el país (G. CLAY, 1974). Se aprecia la subida en más de veinte puntos en los valores medios generales a lo largo de este Siglo XX. Ello ha supuesto el crecimiento de muchas ciudades a la vez que el ascenso demográfico de numerosas áreas metropolitanas, creándose nuevas jerarquías urbanas. Al mismo tiempo se observa el vaciamiento de espacios rurales tradicionalmente más poblados.

b) Las agudas modificaciones sufridas en los sectores productivos. Descenso de los sectores primarios; incremento y, sobre todo, remodelación de la industria, con significati- 
vos cambios en sus implicaciones territoriales. Y, dentro de este panorama, es de resaltar el fuerte tirón que conoce todo el terciario, con implicaciones destacadas en lo que ha dado en llamarse terciario avanzado y cuaternario.

c) Todo ello lleva implícitos significativos procesos de especialización funcional que afectan a amplias parcelas de su territorio. Eso sucede en medio de una sociedad desarrollada que, es capaz de asumir los fuertes costes económicos implícitos en los referidos cambios espaciales de la población.

d) Tampoco debe olvidarse la existencia de amplios territorios caracterizados por sus buenas condiciones de riquezas naturales, infrautilizadas hasta tiempos recientes, junto a casos donde se daban situaciones contrapuestas.

e) Igualmente tienen lugar durante los últimos decenios tendencias que desembocan en nuevas movilidades de naturaleza étnica, más complejas y variadas que las anteriores (NATHAN, G., 1979; ALLEN, J., TURNER, E.J., 1987; LAWRENCE, F., 1990). Importantes colectivos humanos, que hasta hace pocos años se habían visto relegados a vivir en ciertas áreas, ahora han preferido desplazarse hacia otras, más sugestivas. Todo lo cual cabe interpretarlo como una nueva faceta del denominado «melting pot» típico de USA.

De todas maneras, a pesar de las fuertes modificaciones señaladas que han tenido lugar en este Siglo, si bien han supuesto una redistribución de los efectivos demográficos, dando lugar a una realidad menos acusada que la presente, son todavía fuertes los contrastes existentes, que, junto a otras múltiples circunstancias, anuncian nuevas modificaciones futuras.

\section{Bibliografía consultada}

ADAMS, J.S. (ed.): Contemporary Metropolitan America. Cambridge, Mass. Ballinger, 4 vols.

ALLEN, J.; TURNER, E.J. (1987): We the People: An Atlas of American's Ethnic Diversity. Nueva York, MacMillan.

ARMAND, L.; MARTIN, D.; TOINET, M.F. (1980): Les Etats-Unis et leurs populations. Ed. Complexe, Paris.

BETHEMONT, J.; BREUIL, J.M. (1989): Les Etats-Unis: une géographie régionale. Masson, Paris.

BIRDSALL, S.; FLORIN, T. (1992): Regional Landscapes of the United States and Canada. Nueva York, John Wiley \& Sons, $4^{\mathrm{a}}$ ed.

BODNAR, J. (1985): The Transplanted. A History of Inmigrant in Urban America. Indiana University Press, Bloomington, (In.).

BRUNN, S.; WHEELER, J.D. (1980): The Metropolitan System: Present and Future. Nueva York, Halsted Press, V.H., Winston.

CLARK, D. (1985): Post Industrial America: A Geographical Perspective. Nueva York, Methuen.

CLAY, G. (1974): Close-up; How to read the American city. Nueva York, Praeger.

DEBLIT, H.J.; MULLER, P.D. (1992): Geography: region \& concepts. Nueva York, John Wiley, $6^{\text {a }}$ ed. revisada, (vid. cap. 3).

FREY, W.; SPEARE, A. (1988): Regional and metropolitan Growth and Decline in the United States. Nueva York, Russel Sage Foundation.

GHORRA-GOBIN, C. (1987): Les Américains et leur territoire. Mythes et réalités. Paris, La Documentation Française, $\mathrm{n}^{\circ}$ 3, 114 pp.

GHORRA-GOBIN, C. (1993): Les Etats-Unis: Espace, environnement, societé, ville. Paris, Nathan Université.

GOTMANN, J. (1961): Megalopolis: The Urbanized Northeaster Seabord of the United States. Cambridge Mass. MIT pres.

HANSEN, M.L. (1948-51): The Immigrant in American History. The Atlantic Migration, 1607-1860. Cambridge, Mass. MIT, Pres. 
HOLLANDER, A.N.J. den; SKARD, S. (1968): American Civilisation. An Introduction. Bristol, Longman, $523 \mathrm{pp}$.

JEANNINE, B. (1980): America! America! Trois siècles d'emigration aux Etats Unis (1620-1920). Paris, Gallimard.

JOHNSTON, R.J. (1982): The American Urban System: A Geographical Perspective. Nueva York, Methuen.

KNOX, P.I., et al. (1988): The United States: a Contemporary Human Geography. Longman, Londres, Nueva York.

LAWRENCE, F. (1990): The American Kaleidoscope: Pluralism and the Civic Culture. Middletown, Wesleyan University Press.

MCHUGH, K. (1989): «Hispanic Migration and population Redistribution in the U.S.». The Professional Geographer, № 41, pp. 429-39.

MITCHELL, R.; GROVES, P. (eds.) (1987): North America: The Historical Geography of a Changing Continent. Totowa N.J., Rowman \& Littlefield.

MULLER, P.O. (1986): «Transportation and urban Growth: The Shaping of the American Metropolis». Focus, no 36, pp. 8-17.

NATHAN, G.; PATRIK, M.D. (1979): Beyond the Melting pot. Cambridge Mass. MIT Pres, $2^{\mathrm{a}}$ ed.

OXFORD REGIONAL ECONOMIC ATLAS OF THE UNITED STATES AND CANADA (1994); Nueva York, Oxford University Press, $3^{\mathrm{a}}$ ed. rev.

PATERSON, J.H. (1989): North America: A Geography of Canada and the United States. Oxford University Press, Nueva York, $8^{\mathrm{a}}$ ed.

SCHLESINGER, A.M.J. (1971): L'Ere de Roosevelt. Paris, Denoël, 3 vols.

TASSIN, Cl. (1994): «New York, du rêve blessé au rêve réactualisé?». L'Information Géographique, vol. 58, pp. 133-142.

THOMSON, R. (1969): The Golden Door. A History of the United States of America, 1607-1945. Londres, Alman \& Son Limited.

TOINET, M.F. (1990): L'Etat des Etats-Unis. Paris, La Decouverte.

WEISS, R. (1990): The American Myth of Succes. Basic Books, Nueva York, $3^{\mathrm{a}}$ ed.

YEATES, M. (1980): North American Urban Patterns. Silver Spring, Md. \& Londres. 
